\title{
Pulse Oximeter Monitoring Bracelet for COVID-19 Patient Using Seeeduino
}

\author{
Rahmalisa Suhartina ${ }^{1}$, Tomy Abuzairi ${ }^{2 *}$ \\ ${ }^{1}$ Biomedical Engineering, Department of Electrical Engineering, Faculty of Engineering, Universitas Indonesia, Depok, Indonesia \\ ${ }^{2}$ Electrical Engineering, Department of Electrical Engineering, Faculty of Engineering, Universitas Indonesia, Depok, Indonesia
}

\begin{tabular}{|c|c|}
\hline ARTICLE INFO & ABSTRACT \\
\hline Article history: & \multirow{6}{*}{$\begin{array}{l}\text { The increase in positive cases of COVID-19 makes it grave to monitor the } \\
\text { level of oxygen saturation in the blood (SPO2) of COVID-19 patients. The } \\
\text { purpose is to prevent silent hypoxia, which lowers oxygen levels in the blood } \\
\text { without symptoms. In general, a conventional pulse oximeter is a clip that is } \\
\text { clamped on a finger to measure SPO2 levels and heart rate per minute (HR). } \\
\text { This research aims to design a compact pulse oximeter monitoring bracelet. } \\
\text { The main components of the pulse oximeter monitoring bracelet are the } \\
\text { Seeeduino XIAO microcontroller, MAX30100 sensor, and OLED display. The } \\
\text { method of collecting data on ten people using a conventional pulse oximeter } \\
\text { and prototype device to measure SPO2 and HR levels the interval } 30 \text { seconds } \\
\text { were a taken measurement. The results show that the Pearson correlation value } \\
\text { for SPO2 and HR are - } 0.73 \text { and 0.98, respectively. These results demonstrated } \\
\text { that there is a strong relationship between variables and sufficient linearity. In } \\
\text { addition, a pulse oximeter monitoring bracelet is easy to use and low-costs, } \\
\text { which makes it an attractive option for the successful implementation of such } \\
\text { monitoring SPO2 and HR of COVID-19 patients. }\end{array}$} \\
\hline Received April 06, 2021 & \\
\hline Revised April 18, 2021 & \\
\hline Accepted April 22, 2021 & \\
\hline Keywords: & \\
\hline $\begin{array}{l}\text { COVID-19; } \\
\text { Oxygen saturation; } \\
\text { Heart rate; } \\
\text { Seeeduino; } \\
\text { MAX30100 }\end{array}$ & \\
\hline
\end{tabular}

This work is licensed under a Creative Commons Attribution-Share Alike 4.0

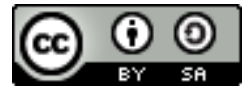

Tomy Abuzairi

Electrical Engineering, Department of Electrical Engineering, Faculty of Engineering, Universitas Indonesia, Indonesia Email: tomy.abuzairi@ui.ac.id

\section{INTRODUCTION}

The severe acute respiratory syndrome, coronavirus disease 2019 (COVID-19), has been spread around the world and is therefore regarded as a pandemic. As at April 18, 2021, over 140 million cases and 3.1 million deaths were recorded after the pandemic began [1]. In consent with the implementation of the COVID-19 prevention and control guidelines from the Indonesian Ministry of Health, self-quarantine is applied to people with no symptoms, people under management, and patients under surveillance. In patients who are positive for COVID-19, monitoring activities need to be carried out to avoid worsening symptoms [2].

Generally, human body temperature is used for monitoring COVID-19 patients [3][4]. However, for longperiod monitoring, human body temperature is difficult to monitor because it is affected by the temperature of the environment and patient activity. Another monitoring is by monitoring the level of oxygen saturation in the blood (SPO2) and heart rate (HR). SPO2 and HR are used in order to prevent silent hypoxia, which results in lowering oxygen levels in the blood without symptoms, causing tissue damage in the body, and can lead to complications such as respiratory failure or sudden death if left untreated.

A pulse oximeter is a tool used to monitor SPO2 and HR, generally the use of a pulse oximeter device that is clamped on the finger [5]. The noninvasive optical technique of pulse oximeter measurement is the absorption of a spectrum of light of different wavelengths (at $660 \mathrm{~nm}$ to $940 \mathrm{~nm}$ ) on oxyhemoglobin and deoxyhemoglobin [6][7]. Basically, a pulse oximeter uses LED light to determine oxygen saturation by comparing how much red and infrared light is absorbed in blood [8]. In the development of the pulse oximeter tool, it has a variety of models, which are clamped at the fingertips, in the form of a ring, and most recently in the form of a smartwatch. However, the conventional pulse oximeter models that are clamped at the fingertips may not be very convenient for continuous monitoring over long periods of time [8][9]. This study aims to 
build a pulse oximeter monitoring bracelet prototype that is comfortable for long measurements and can ease monitoring of SPO2 and HR in COVID-19 patients.

\section{METHOD}

\subsection{Oxygen Saturation (SPO2)}

Oxygen saturation is the percentage ratio between the amount of oxygenated hemoglobin in the arteries to the amount of deoxyhemoglobin and oxyhemoglobin. Oxygen saturation values range from 95-100\% and can be measured using a non-invasive method, specifically pulse oximeter [10][11].

\subsection{Pulse Oximeter}

Pulse oximetry has a light detection sensor to measure oxygen saturation and HR by combining two technologies, namely spectrophotometry and plethysmography (PPG) [10][12]. Noninvasive pulse oximeter generally uses PPG technology which has two modes, namely transmission, and reflectance, where the difference in the location of the pulse oximeter sensor is LED and photodetector (PD). In the transmission mode, the location of the LED and PD is opposite where the LED light penetrates the network, and then the light intensity is transmitted and detected by the PD. Whereas in front-line LED and PD reflectance mode, both have the same way of working by emitting light on a certain wave by blood or tissue, and PD detects the light intensity [13][14][15].

\subsection{Prototype Design}

In designing the prototype, the stages perform are the design of the wiring tool and printing on the PCB. Fig. 1 shows a schematic circuit of the pulse oximeter monitoring. In this research, we use the Seeduino XIAO development board that has powerful performance using ATSAMD21G18A-MU as a microcontroller with low power. The design has a small size as a thumb with good performs in processing but requires less power and can be used for wearable devices [16]. The MAX30100 sensor module, including LED (Red-Infrared), drive circuit, and PD, will convert the intensity of the transmitted light into SPO2 and HR values [17]. The OLED SSD1306, with a size of $128 \mathrm{~mm}$ x $64 \mathrm{~mm}$, then displays the results of the SPO2 and HR in real-time [18]. Fig. 2 shows the PCB 3-D design and the implementation of the prototype pulse oximeter monitoring bracelet. The pulse oximeter monitoring is designed as a bracelet because it can be a wearable device and can be long-period monitoring [19].

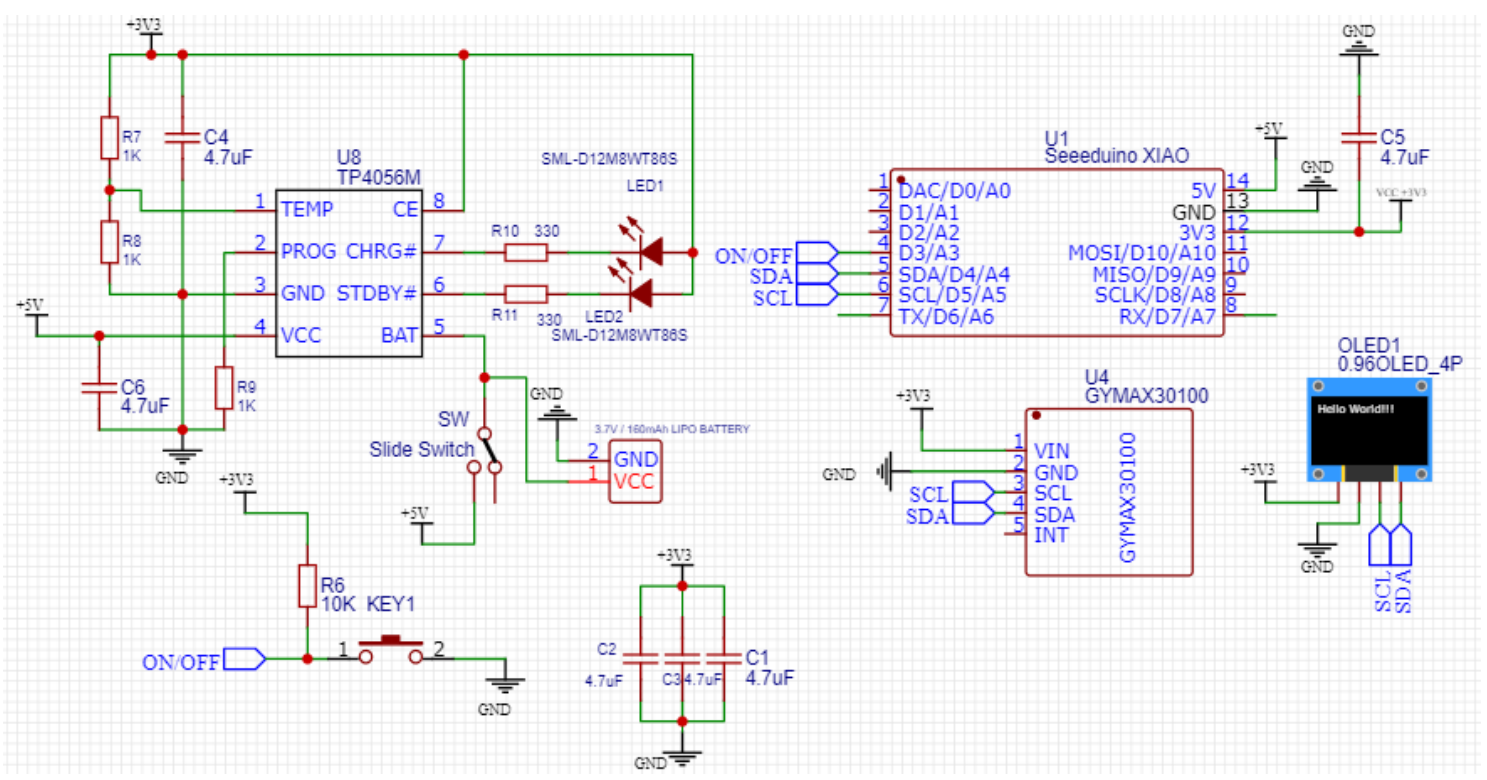

Fig. 1. Schematic circuit of the prototype pulse oximeter monitoring bracelet

\subsection{Calculation Pulse Oximeter}

A pulse oximeter is a device that can measure your pulse and oxygen saturation in the blood. Oxygen concentration is measured by calculating the ratio between absorbed light from IR LED (940 nm) and Red LED $(660 \mathrm{~nm})$ [20]. In short, SPO2 is defined as the ratio of the oxygenated Hemoglobin level over the total Hemoglobin level, as shown in (1). The ratio R between these two wavelengths is defined with (2). Light transmits DC such as skin, bone, muscle. For light transmits AC such as arterial blood. 


$$
\begin{gathered}
\text { SpO2 }=\frac{H b O 2}{\text { Total Hb}} \times 100 \% \\
R=\frac{I_{A C}^{\lambda 1} / I_{D C}^{\lambda 1}}{I_{A C}^{\lambda 2} / I_{D C}^{\lambda 2}}
\end{gathered}
$$

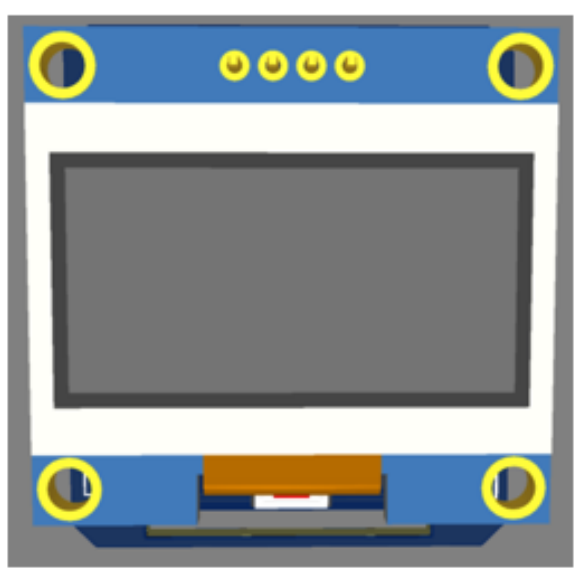

(a)

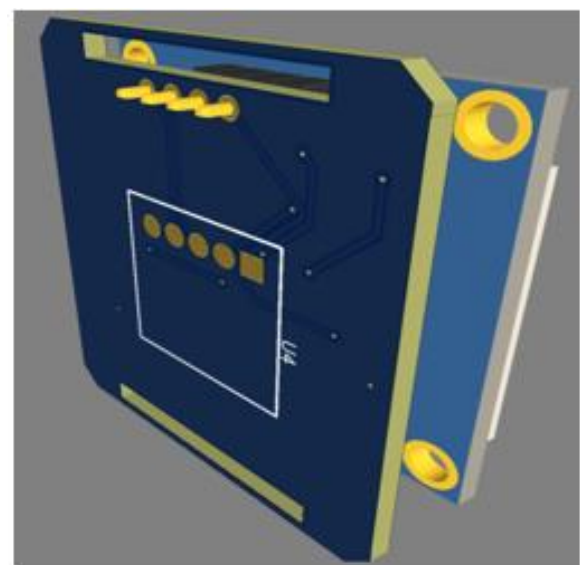

(b)

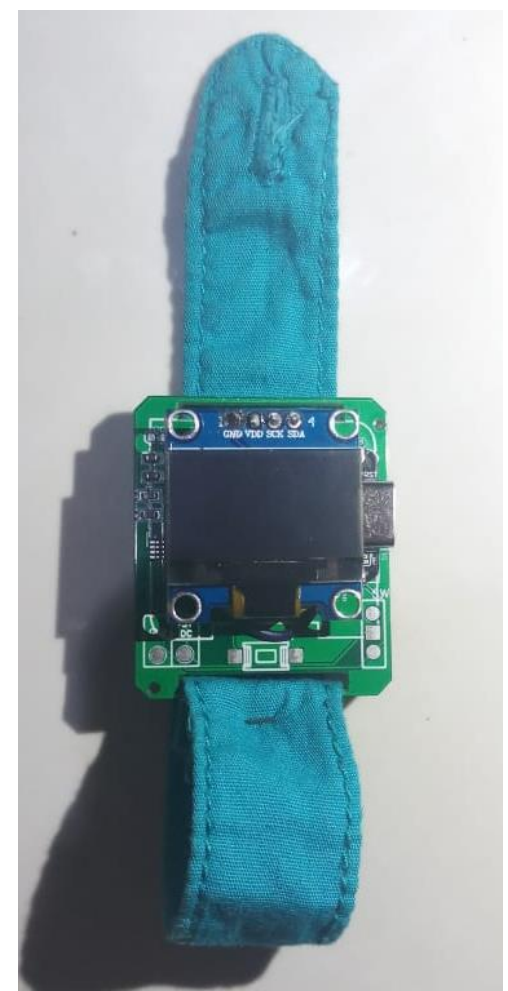

(c)

Fig. 2. Top (a) and back (b) 3-D PCB design view, (c) Implementation design of the pulse oximeter monitoring bracelet

\subsection{Pearson Correlation Coefficient}

Correlation is a statistical method used to assess the probability of a linear relationship between two continuous variables $\mathrm{x}$ or $\mathrm{y}$ [4]. It is to calculate the Pearson correlation coefficient as $r$ for a sample statistic [21]. The correlation coefficient can be positive in the range 1 to -1 . If the value is close to 1 , then there is a strong relationship, and if the value is close to 0, then the closeness between the variables is weak [22]. Equation (3) shows the Pearson correlation coefficient where $x_{i}$ and $y_{i}$ are the values of prototype and reference. 


$$
r=\frac{\sum_{i}^{n}\left(x_{i}-x\right)\left(y_{i}-y\right)}{\sqrt{\left[\sum_{i=1}^{n}\left(x_{i}-\bar{x}\right)^{2}\right]\left[\sum_{i=1}^{n}\left(y_{i}-\bar{y}\right)^{2}\right]}}
$$

\section{RESULTS AND DISCUSSION}

The data collection using a compact bracelet pulse oximeter monitoring prototype is shown in Fig. 3. At the time of collecting data, a prototype device is used on the wrist of the subject, and a conventional pulse oximeter is clipped to the fingertip. Conventional pulse oximeter tool (Yobekan, calibrated standard) is used as a reference of SPO2 and HR values. Ten subjects with sampling time intervals every 30 seconds were conducted pulse oximeter measurement. The subjects were children ten years old, adults 20-35 years old to 64 years old. Activities before monitoring each subject in a condition where they finished working from home, finished taking a nap, and studied online at home. Fig. 4 and Fig. 5 show that linear relationships between prototype and reference pulse oximeter.

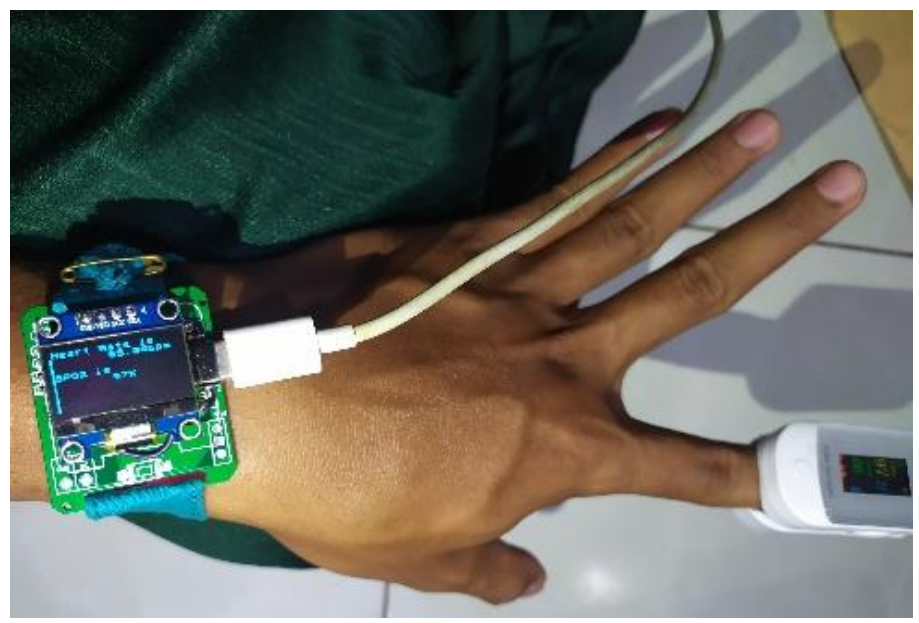

Fig. 3. Installation of a prototype device with a conventional pulse oximeter

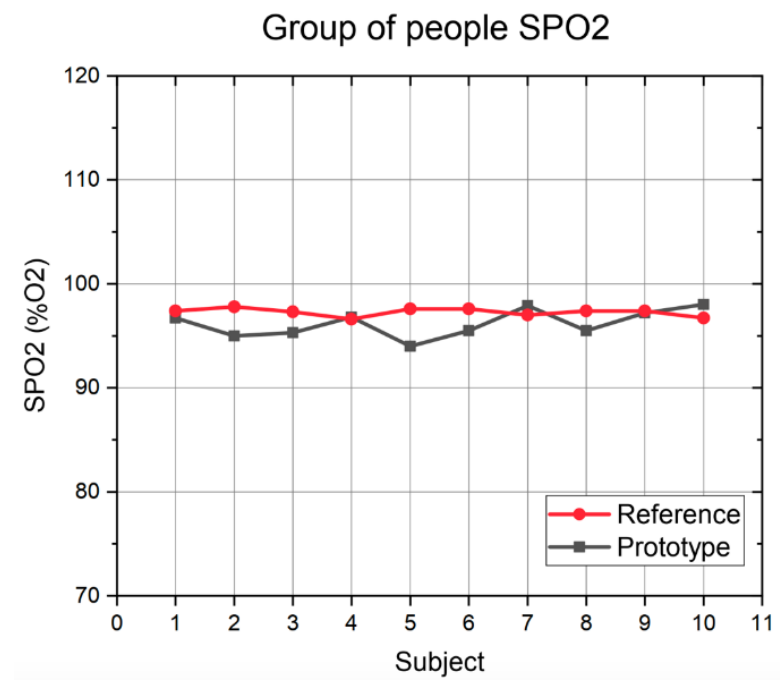

Fig. 4. Comparison SPO2 between the prototype and reference.

Table 1 shows the data average of SPO2 measurements. From the results of measuring the average SPO2 by calculating the Pearson correlation, it is obtained with a value of -0.73 , which has a strong accuracy between the value of the prototype device and the conventional pulse oximeter reference device. The calculation is as follow.

- SPO2 Prototype $(P)$ values

$$
\begin{aligned}
& \sum=961.9 \\
& \text { Mean }=96.19
\end{aligned}
$$


$\sum(\mathrm{P}-\mathrm{M}(\mathrm{P}))^{2}=15.809$

- $\quad$ SPO2 Reference $(R)$ values

$\sum=972.7$

Mean $=97.3$

$\sum(\mathrm{R}-\mathrm{M}(\mathrm{R}))^{2}=1.4$

- Prototype and reference SPO2 combined

$\mathrm{N}=10$

$\sum \mathrm{P}-\mathrm{M}(\mathrm{P}) \times \mathrm{R}-\mathrm{M}(\mathrm{R})=-3.43589$

- $\quad r$ correlation

$r=\frac{-3.43589}{\sqrt{15.809} \times \sqrt{1.4}}=-0.73$

Group of people HR

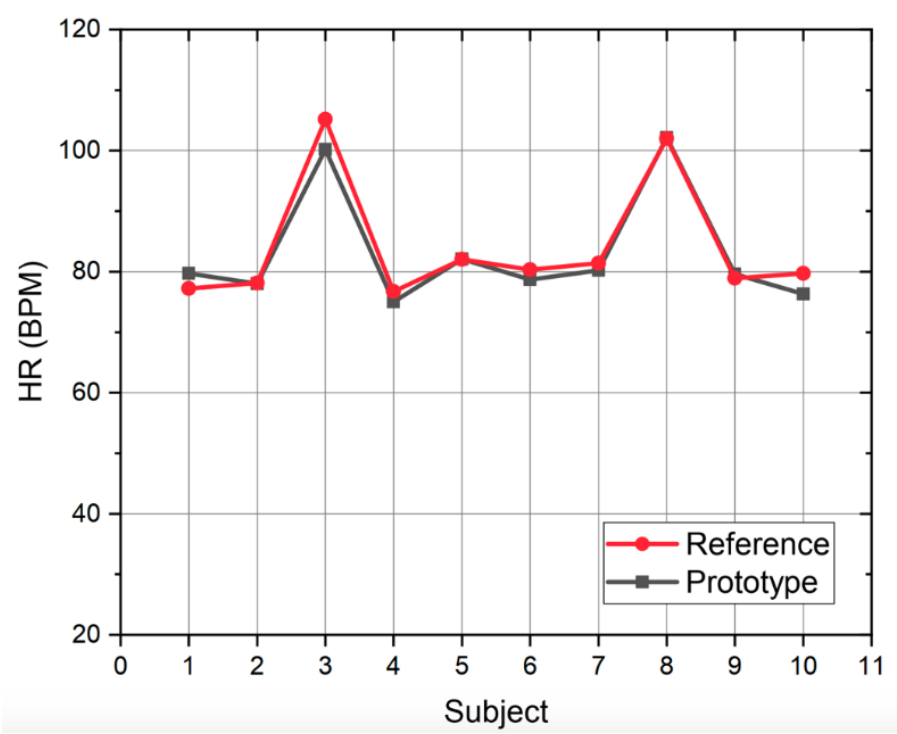

Fig. 5. Comparison HR between the prototype and reference.

Table 1. Data average SPO2 measurements using a prototype device and a pulse oximeter reference device

\begin{tabular}{cccccccc}
\hline Subject & SPO2 $(\mathbf{P})$ & SPO2 $(\mathbf{R})$ & P-M(P) & R-M(R) & P-M(P) x R-M(R) & $(\mathbf{P}-\mathbf{M}(\mathbf{P}))^{\mathbf{2}}$ & $(\mathbf{R}-\mathbf{M}(\mathbf{R}))^{\mathbf{2}}$ \\
\hline 1 & 96.7 & 97.4 & 0.51 & 0.1 & 0.0612 & 0.2601 & 0.0 \\
2 & 95.0 & 97.8 & -1.19 & 0.5 & -0.6188 & 1.4161 & 0.3 \\
3 & 95.3 & 97.3 & -0.89 & 0.0 & -0.0178 & 0.7921 & 0.0 \\
4 & 96.8 & 96.6 & 0.61 & -0.7 & -0.4148 & 0.3721 & 0.5 \\
5 & 94.0 & 97.6 & -2.19 & 0.3 & -0.7008 & 4.7961 & 0.1 \\
6 & 95.5 & 97.6 & -0.69 & 0.3 & -0.2208 & 0.4761 & 0.1 \\
7 & 97.9 & 97.0 & 1.71 & -0.3 & -0.4788 & 2.9241 & 0.1 \\
8 & 95.5 & 97.4 & -0.69 & 0.1 & -0.0828 & 0.4761 & 0.0 \\
9 & 97.2 & 97.4 & 1.01 & 0.1 & 0.1212 & 1.0201 & 0.0 \\
10 & 98.0 & 96.7 & 1.81 & -0.6 & -1.0498 & 3.2761 & 0.3 \\
\hline$\sum$ & $\mathbf{9 6 1 . 9}$ & $\mathbf{9 7 2 . 7}$ & & & $\mathbf{- 3 . 4 0 2 0}$ & $\mathbf{1 5 . 8 0 9}$ & $\mathbf{1 . 4}$ \\
\hline Mean (M) & $\mathbf{9 6 . 1 9}$ & $\mathbf{9 7 . 3}$ & & & & & \\
\hline
\end{tabular}

Table 2 shows the data average of HR measurements. From the results of measuring the average HR by calculating the Pearson correlation, it is obtained with a value of 0.98 , which has a strong accuracy between the value of the prototype device and the conventional pulse oximeter reference device. The calculation is as follow.

- HR Prototype $(P)$ values

$\sum=832.0$

Mean $=83.20$

Pulse Oximeter Monitoring Bracelet for COVID-19 Patient Using Seeeduino (Rahmalisa Suhartina) 
$\sum(\mathrm{P}-\mathrm{M}(\mathrm{P}))^{2}=847.10$

- HR Reference $(R)$ values

$\sum=841.5$

Mean $=84.15$

$\sum(\mathrm{R}-\mathrm{M}(\mathrm{R}))^{2}=976.67$

- Prototype and reference HR combined

$\mathrm{N}=10$

$\sum \mathrm{P}-\mathrm{M}(\mathrm{P}) \times \mathrm{R}-\mathrm{M}(\mathrm{R})=891.4429$

- $\quad r$ correlation

$$
r=\frac{891.44285}{\sqrt{847.10} \times \sqrt{976.67}}=0.98
$$

Table 2. Data average HR measurements using a prototype device and a pulse oximeter reference device

\begin{tabular}{cccccccc}
\hline Subject & HR $(\mathbf{P})$ & HR $(\mathbf{R})$ & $\mathbf{P - M}(\mathbf{P})$ & $\mathbf{R - M}(\mathbf{R})$ & $\mathbf{P}-\mathbf{M}(\mathbf{P}) \mathbf{x} \mathbf{R}-\mathbf{M}(\mathbf{R})$ & $(\mathbf{P}-\mathbf{M}(\mathbf{P}))^{\mathbf{2}}$ & $(\mathbf{R}-\mathbf{M}(\mathbf{R}))^{\mathbf{2}}$ \\
\hline 1 & 79.7 & 77.2 & -3.50 & -6.95 & 24.34038 & 12.27 & 48.27 \\
2 & 78.0 & 78.1 & -5.20 & -6.04 & 31.41078 & 27.07 & 36.44 \\
3 & 100.2 & 105.2 & 17.00 & 21.05 & 357.81760 & 288.89 & 443.20 \\
4 & 75.0 & 76.7 & -8.20 & -7.45 & 61.09660 & 67.29 & 55.47 \\
5 & 82.1 & 82.0 & -1.10 & -2.15 & 2.36971 & 1.22 & 4.61 \\
6 & 78.7 & 80.3 & -4.50 & -3.85 & 17.32782 & 20.28 & 14.81 \\
7 & 80.2 & 81.4 & -3.00 & -2.75 & 8.25249 & 9.02 & 7.55 \\
8 & 102.2 & 102.0 & 19.00 & 17.85 & 339.13271 & 360.87 & 318.70 \\
9 & 79.6 & 78.9 & -3.60 & -5.25 & 18.90949 & 12.98 & 27.54 \\
10 & 76.3 & 79.7 & -6.87 & -4.48 & 30.78523 & 47.20 & 20.08 \\
\hline$\sum$ & $\mathbf{8 3 2 . 0}$ & $\mathbf{8 4 1 . 5}$ & & & $\mathbf{8 9 1 . 4 4 2 8 5}$ & $\mathbf{8 4 7 . 1 0}$ & $\mathbf{9 7 6 . 6 7}$ \\
\hline Mean (M) & $\mathbf{8 3 . 2 0}$ & $\mathbf{8 4 . 1 5}$ & \multicolumn{7}{c}{} & & \\
\hline
\end{tabular}

\section{CONCLUSION}

Pulse oximeter monitoring bracelet has been successfully designed. The results of pulse oximeter monitoring bracelet measurement in 10 people of different ages show that the Pearson correlation value for SPO2 and HR are -0.73 and 0.98 , respectively. These results demonstrated that there is a strong relationship between variables and sufficient linearity. In addition, a pulse oximeter monitoring bracelet is easy to use and low-costs, which makes it an attractive option for the successful implementation of such monitoring SPO2 and HR of COVID-19 patients.

\section{Acknowledgments}

This work has been supported by Research Grant PDUPT 2021 "Penelitian Dasar Unggulan Perguruan Tinggi" (NKB-214/UN2.RST/HKP.05.00/2021) from the Ministry of Research Republic of Indonesia.

\section{REFERENCES}

[1] CSSEGISandData, "COVID-19 Data Repository by the Center for Systems Science and Engineering (CSSE) at Johns Hopkins University.” https://github.com/CSSEGISandData/COVID-19 (accessed Apr. 18, 2021).

[2] Y. Riza and S. Bambang, "Rancang Bangun Photoplethysmography (Ppg) Tipe Gelang Tangan Untuk Menghitung Detak Jantung Berbasis Arduino," Jurnal Teknik Elektro, vol. 06, pp. 223-231, 2017.

[3] T. Abuzairi, N. I. Sumantri, A. Irvan, and R. M. Mohamad, "Infrared Thermometer on the Wall (iThermowall): an open source and 3-D print infrared thermometer for fever screening," HardwareX, p. e00168, 2020. https://doi.org/10.1016/j.ohx.2020.e00168

[4] M. J. Mnati, R. F. Chisab, A. M. Al-Rawi, A. H. Ali, and A. Van den Bossche, "An open-source non-contact thermometer using low-cost electronic components," HardwareX, vol. 9, p. e00183, 2021. https://doi.org/10.1016/j.ohx.2021.e00183

[5] N. Selvaraj et al., "A novel approach using time-frequency analysis of pulse-oximeter data to detect progressive hypovolemia in spontaneously breathing healthy subjects," IEEE Transactions on Biomedical Engineering, vol. 58, no. 8, pp. 2272-2279, 2011. https://doi.org/10.1109/TBME.2011.2144981

[6] T. Tamura, Y. Maeda, M. Sekine, and M. Yoshida, "Wearable Photoplethysmographic Sensors—Past and Present," pp. 282-302, 2014. https://doi.org/10.3390/electronics3020282

[7] G. Pang and C. Ma, "A Neo-Reflective Wrist Pulse Oximeter," IEEE Access, vol. 2, pp. 1562-1567, 2014. https://doi.org/10.1109/ACCESS.2014.2382179 
[8] L. Aditya, "Rancang Bangun Alat Pengukur Kadar Oksigen Non Invasive Menggunakan Sensor Max30100," Jurnal Ilmiah Elektrokrisna, vol. 8, no. 3, pp. 62-69, 2020.

[9] A. AvakhKisomi, A. Miled, M. Boukadoum, M. Morissette, F. Lellouche and B. Gosselin, "A novel wireless ringshaped multi-site pulse oximeter," 2016 IEEE International Symposium on Circuits and Systems (ISCAS), 2016, pp. 2451-2454. https://doi.org/10.1109/ISCAS.2016.7539088

[10] C. Phillips and M. Gabel, "Wristo2: Reliable Peripheral Oxygen Saturation Readings from Wrist-Worn Pulse Oximeters,” arXiv preprint arXiv:1906.07545, 2019. https://arxiv.org/abs/1906.07545

[11] M. R. Saputra, "Telemonitoring Perburukan Gejala Pada Pdp Covid-19 Karantna Madiri Berbasis Iot," Disertation, Universitas Muhammadiyah Surakarta, 2020.

[12] E. M. G. Rodrigues, R. Godina, C. M. P. Cabrita, and J. P. S. Catalão, "Experimental low cost reflective type oximeter for wearable health systems," Biomedical Signal Processing and Control, vol. 31, no. 1, pp. 419-433, 2017. https://doi.org/10.1016/j.bspc.2016.09.013

[13] M. Nitzan, A. Romem, and R. Koppel, "Pulse oximetry: Fundamentals and technology update," Medical Devices: Evidence and Research, vol. 7, no. 1, pp. 231-239, 2014. https://doi.org/10.2147/MDER.S47319

[14] W. Wu, F. N. Stapelfeldt, S. Kroker, H. S. Wasisto, and A. Waag, "A Compact Calibratable Pulse Oximeter Based on Color Filters: Towards a Quantitative Analysis of Measurement Uncertainty," IEEE Sensors Journal, vol. 21, no. 6, pp. 7522-7531, 2021. https://doi.org/10.1109/JSEN.2020.3048118

[15] N. I. Martemyanova, N. D. Turgunova, and A. N. Aleinik, "Development and research of reflectance pulse oximeter," 2014 12th International Conference on Actual Problems of Electronic Instrument Engineering, APEIE 2014 Proceedings, pp. 500-502, 2015. https://doi.org/10.1109/APEIE.2014.7040732

[16] Seeed Studio, "Seeeduino XIAO." https://wiki.seeedstudio.com/Seeeduino-XIAO (accessed Apr. 06, 2021).

[17] Maxim integrated, "MAX30100 - Pulse Oximeter and Heart-Rate Sensor IC for Wearable Health." 2014, Accessed: Apr. 21, 2021. [Online]. Available: https://datasheets.maximintegrated.com/en/ds/MAX30100.pdf

[18] “Adafruit_SSD1306," Github, Aug. 18, 2020. https://github.com/adafruit/Adafruit_SSD1306

[19] K. Devara, S. Ramadhanty, and T. Abuzairi, "Design of wearable health monitoring device," AIP Conference Proceedings, AIP Publishing LLC, vol. 1933, no. 1, p. 040022, 2018. https://doi.org/10.1063/1.5023992

[20] J. Wan, Y. Zou, Y. Li and J. Wang, "Reflective type blood oxygen saturation detection system based on MAX30100," 2017 International Conference on Security, Pattern Analysis, and Cybernetics (SPAC), 2017, pp. 615619. https://doi.org/10.1109/SPAC.2017.8304350

[21] M. M. Mukaka, "Statistics corner: A guide to appropriate use of correlation coefficient in medical research," Malawi Medical Journal, vol. 24, no. 3, pp. 69-71, 2012.

[22] A. M. Kelly, R. McAlpine, and E. Kyle, "How accurate are pulse oximeters in patients with acute exacerbations of chronic obstructive airways disease?," Respiratory Medicine, vol. 95, no. 5, pp. 336-340, 2001. https://doi.org/10.1053/rmed.2001.1046

\section{BIOGRAPHY OF AUTHORS}

Rahmalisa Suhartina received bachelor electromedical engineering from Politeknik Kementerian Kesehatan Jakarta II, in 2017. She is currently pursuing the magister's degree in biomedical engineering at, Department of Electrical Engineering, Faculty of Engineering, Universitas Indonesia. Email: rlisast@gmail.com

Tomy Abuzairi received the B.Eng degree in electrical engineering from the Department of Electrical Engineering, Universitas Indonesia, in 2009, the M.Sc degree (double degree program) in optoelectronic engineering and electrical engineering from National Taiwan University of Science and Technology, and Universitas Indonesia, in 2012, the Ph.D. degree (double degree program) in a graduate school of science and technology, and electrical engineering from Shizuoka University and Universitas Indonesia, in 2016. He joined the Department of Electrical Engineering, Universitas Indonesia, in 2017, where he is currently an Assistant Professor. He has authored or co-authored over 40 articles published in refereed journals and conferences. He holds several patents for instrumentation and sensor. His research interests include biomedical instrumentations, optoelectronic, plasma technology, nanotechnology, and sensor. Email: tomy.abuzairi@gmail.com 